\title{
INTERACCION ENTRE GENOTIPOS DE FRIJOL Y AISLAMIENTO DE Rhizoctonia solani KUHN. HEREDABILIDAD DE LA RESISTENCIA A LA MUSTIA HILACHOSA Thanatephorus cucumeris (FRANK) (DONK) EN CULTIVARES Y POBLACIONES F Y F $_{2}$ DE FRIJOL COMÚN Phaseolus vulgaris L.1
}

\author{
Emigdio Rodríguez 2 , Adolfo Garda ${ }^{3}$, Gustavo Frías ${ }^{4}$, Steve Beebe ${ }^{5}$
}

\begin{abstract}
RESUMEN
Interacción entre genotipos de frijol y aislamiento de Rhizoctonia solani Kuhn. heredabilidad de la resistencia a la mustia hilachosa Thanatephorus cucumeris (Frank) (Donk) en cuItivares y poblaciones $F$, y F2 de frijol común Phaseolus vulgaris $\mathbf{L}$. Se inocularon genotipos mesoamericanos y andinos de frijol común con micelio de Thanalephorus cucumeris (Frank), Donk, con el objeto de determinar: 1. La interacción entre diferentes aislamientos de Rhizoclonia solani, Kuhn y genotipos de frijol de dos acervos genéticos diferentes; 2 . La heredabilidad de la resistencia a la mustia hilachosa; 3. La complementación génica que existe entre el acervo mesoamericano y andino respectivamente. Los resultados encontrados en el presente estudio fueron los siguientes: Las cepas varían dependiendo de su lugar de origen. Así las cepas de Colombia y República Dominicana causan el menor daño a las plantas de frijol, el aislamiento Panamá \#1 es moderadamente lento y los de Panamá \#2 y Costa Rica son los que mayor daño cau-san a este cultivo. La cepa RS-32-Cr resultó ser la más virulenta de todas. La heredabilidad mostrada por los cruzamientos fue alta, lo que nos indica que si existe complementación génica entre el acervo mesoamericano y andino respectivamente. El cruzamiento AFR-251 x BAT-1155, en forma directa y recíproca, mostraron diferencias tanto en la $\mathrm{F}_{1}$ como en la $\mathrm{F}_{2}$ lo que nos indica que la resistencia a la enfermedad está controlada tanto por gcnes del citoplasma corno por genes del núcleo. El tipo de resistencia que mostraron los diferentes cruzamientos evaluados fue el de resistencia horizontal y no el de resistencia vertical.
\end{abstract}

\begin{abstract}
Interaction among bean genotypes and isolation of Rhizoctonia solani Kuhn. heritability of resistance to webblight Thanatephorus cucumeris (Frank) (Donk) in cuItivars and $F_{1}$ and $F_{2}$ populations of common bean (Phaseolus vulgaris L. Meso-american and Andean eommon bean genotypes were inoeulated with mycellium of Thanatephorus cucumeris (Frank), Donk to determine: 1- The interaction among different isolations of Rhizoclonia solani, Kuhn and bean genotypes from two genetic pools, 2- the heritability of resistance to web-blight and 3- the existing genic completion between the meso-american and Andean pools, respeetively. The results found in this experiment were as follows : the strains vary depending of the origin site. Thus, the Dominican Republic and Colombian strains cause a lesser damage to the bean plants. The Panama \# 1 isolation is moderately slow, and the Panama \# 2 and Costa Rica caused the largest damage to the crop. The RS32-Cr strain was the most virulent of all. The heritabiJity shown by crossing was high which indieates that there is genic completion between the meso-ameriean and the Andean pools, respectively. The erossing of of AFR-251 x BAT-1155, in a direct and reciprocal way, showed differences in the $F_{1}$ and the $\mathrm{F}_{2}$, indicating that the resistance to the disease is controlled by cytoplasmie genes as by nuclear genes. The type of resistance shown by the different evaluated crosses was horizontal and not vertical resistance.
\end{abstract}

\section{INTRODUCCION}

La mustia hilachosa del frijol común Phaseolus vulgaris L. producida por el hongo Thanatephorus cucume- ris (Frank) Donk., representa una de las principales limitantes de este cultivo en zonas tropicales con altas precipitaciones y temperaturas. En esta zona es considerada como la enfermedad más destructiva del cultivo de frijol

\footnotetext{
1 Presentado en la XL Reunión Anual del PCCMCA en Costa Rica, América CentraL 13 al 19 de marzo, 1994.

2 Ingeniero Agrónomo. M. Sc. en Fitomejoramiento. Investigador de la Región Occidental. IDIAP.

3 Maestro en Ciencias en Fitomejoramiento. Maestro investigador U.A.A.A.N. Buenavista, Saltillo, México.

4 Dr. en Fitopatología. Maestro investigador U.A.A.A.N. Buenavista. Saltillo, México.

5 Dr. en Fitomejoramiento, CIAT, Cali, Colombia.
} 
común, por la defoliación rápida y drástica que causa a las plantas afectadas, provocando en la mayoría de los casos pérdida total de la cosecha (Gálvez et al., 1980; Rodríguez, E., 1993).

Los síntomas de la enfermedad son manchas acuosas de 1-3 mm de diámetro. A medida que las manchas crecen, su color se torna más claro que el tejido sano circundante, hasta tomar una coloración café delimitada por un borde más oscuro. Posteriormente las lesiones coalescen pudiendo cubrir la totalidad de la hoja, dando la apariencia de haber sufrido escaldaduras por agua caliente. En las vainas la infección se manifiesta como manchas de forma irregular, de color café a negro, las cuales pueden causar la destrucción total de la vaina. Sobre el tejido enfermo se producen esclerocios y basidiosporas, aparentemente la producción de uno u otro tipo de propágulo depende de las condiciones ambientales predominantes, como son: la precipitación, humedad relativa, humedad en el suelo y temperatura (Rodríguez, E., 1993).

En la actualidad, la enfermedad se encuentra en todos los países de América Tropical y se indica como una de las principales limitantes en la región Amazónica de Brasil, el sureste de México y la región de Africa Oriental. En algunos países la mustia adquiere cada día mayor importancia económica debido al desplazamiento del cultivo del frijol a las zonas bajas húmedas, en donde la enfermedad se ve favorecida por lluvias intensas y temperaturas altas. En algunas regiones de Centroamérica, el cultivo del frijol ha sido abandonado debido a la severidad de la enfermedad (Rodríguez, E., 1993).

Incorporar resistencia genética a líneas y cultivares de frijol, con el cual se abata el patógeno, es un componente importante en el control de esta enfermedad, pero no se ha podido avanzar con rapidez. La capacidad de adaptación del patógeno y el gran número de hospederos son las principales razones que han hecho difícil encontrar resistencia a este patógeno (Acosta, 1988; Rodríguez, 1992).

Se tenían muchas dudas de la posibilidad de aumentar la resistencia a este patógeno hasta que se evaluó el EP (Ensayo Preliminar) del CIAT en 1981. En este vivero, se pudo observar variabilidad amplia y consistente, y en particular unas líneas que tenían como progenitor a Turrialba. A partir de este año el número de cruzas aumentó, con el propósito de encontrar resistencia superior a través de segregación transgresiva. Así se pudo demostrar una amplia ventaja de la cruza HT -7716, sobre el testigo "resistente" Porrillo 70 (Beebe, 1986; Rodríguez, 1992).

En la evaluación del Vivero Internacional de Mustia 1988, compuesto por 100 líneas, ninguna superó significativamente la resistencia de Talamanca, testigo que ha sido utilizado desde 1983, lo que sugiere que los intentos por mejorar el nivel de resistencia a mustia, hasta esta fecha, no han tenido éxito; probablemente por la estrecha variabilidad genética del germoplasma utilizado y por la ineficiencia de las evaluaciones de campo para tamizar poblaciones numerosas (Rodríguez, 1992).

Desde la creación del VIM se han detectado algunos genotipos de frijol que reaccionan como muy susceptibles en ciertos países, mientras que en otros presentan un alto grado de resistencia a la enfermedad. Una de las hipótesis para explicar esta diferencia es que en los países en que se siembra el VIM, existen poblaciones de $R$. solani más compatibles con unas variedades que con otras (Frías 1991; Rodríguez, 1992).

Los resultados encontrados en el estudio de la variabilidad patogénica de Thanatephorus cucumeris $=$ Rhizoctonia solani, agente causal de la mustia hilachosa del frijol sugieren que la reacción de una variedad puede variar de un lugar dependiendo de la población del patógeno en la región donde se evalúa el material. Esto y el efecto que la precipitación tiene en la reacción de la resistencia deberán se considerados en los esquemas de mejoramiento genético de la resistencia a la mustia hilachosa (Rodríguez, 1993).

En evaluaciones de germoplasma promisorio, proveniente de CIAT, realizadas en Panamá durante los años 1988, 1989 y 1990 se han tamizado más de 1500 líneas. Encontrándose que los materiales AFR-251 y PVA-800 han mostrado reacción de resistencia a la mustia hilachosa con un porcentaje de severidad de 5 y 15 porciento respectivamente. El rendimiento obtenido para estos cul- 
tivares ha sido de 2,751 y $1591 \mathrm{~kg}$.respecti vamente, mientras que el testigo local (Var. Barriles) mostró hasta 100 por ciento de severidad y rendimiento desde $\mathrm{O} \mathrm{kg} / \mathrm{ha}$ hasta 468 kg/ha (Rodríguez y González, 1988, 1989 Y 1990).

Los objetivos de este trabajo fueron: 1. Determinar la interacción existente entre diferentes aislamientos de $R h i$ zoctonia solani, Kuhn y genotipos de frijol de dos acervos genéticos diferentes, 2. Determinar la heredabilidad de la resistencia a la mustia hilachosa encontrada en dos cultivares de frijol de diferente origen, producto de cruzamientos realizados con materiales intermedios y susceptibles a la enfermedad, 3. Determinar los efectos de complementación génica que existe entre el acervo mesoamericano y andino respectivamente, y las siguientes hipótesis: 1. Los aislamientos de Rhizoctonia solani obtenidos en cuatro países de la región de Centroamérica y el Caribe ocasionan igual efecto en los cultivares de frijol independientemente del origen de los mismos, 2. La heredabilidad de la resistencia a la mustia hilachosa está dada por genes de herencia simple que pueden ser transmitidos a variedades susceptibles e intermedias que actualmente se cultivan en áreas frijoleras de la región de Centroamérica y el Caribe, 3. Las líneas obtenidas de progenitores resistentes de origen Mesoamericano poseen los mismos genes de resistencia que las obtenidas de progenitores resistentes de origen Andino.

\section{MATERIALES Y METODOS}

\section{Ubicación}

El presente trabajo se llevó a cabo en las instalaciones de la Universidad Autónoma Agraria "Antonio Narro" (UAAAN) ubicada en Buenavista, Saltillo, Coahuila, México. Se encuentra entre las coordenadas geográficas $25^{\circ} 23^{\prime}$ de latitud norte y $101^{\circ} 03^{\prime}$ de longitud oeste, con una altitud de $1743 \mathrm{msnm}$, temperatura promedio anual de $16,7^{\circ} \mathrm{C}$ y precipitación anual de $459 \mathrm{~mm}$.

\section{Material Genético a Evaluar}

En el experimento número uno, donde se determinó la interacción existente entre aislamientos de Rhizoctonia solani, Kuhn y genotipos de frijol de dos acervos genéticos diferentes, se evaluaron las variedades y poblaciones F) que se muestran en el Cuadro 1.

Para el experimento número dos, donde se midió la heredabilidad a la mustia hilachosa, se utilizaron los cultivares que se observan en el Cuadro 2.

Para el experimento tres, donde se midieron los efectos de complementación génica, se utilizaron los cultivares que se presentan en el Cuadro 3.

En las instalaciones de CIAT, Cali, Colombia, se procedió a realizar los cruzamientos combinando materiales de diferente origen y de diferente reacción ante el ataque del patógeno, así como también cruzamientos de materiales del mismo origen con diferente grado de reacción a la enfermedad.

Posteriormente en la UAAAN, en las instalaciones del programa de frijol, se realizó el avance generacional de dichas plantas hasta alcanzar las poblaciones $\mathrm{F}_{2}$.

\section{Evaluación de la Severidad de la Enfermedad}

Se utilizó la escala internacional de evaluación de mustia propuesta por el grupo de mejoradores que trabajan en busca de la resistencia genética a la mustia hilachosa y la cual fue aceptada por el CIAT y que se encuentra en el Cuadro 4.

Se estimó visualmente el area foliar en cada hoja que fue afectada por el patógeno, dicho daño fue expresado en porcentaje el cual fue transformado a una variable no paramétrica para el caso del experimento uno, mientras que para el experimento dos y tres los datos fueron transformados a través de seno ${ }^{1} \sqrt{ } / 100 * 57,2958$ y el análisis de varianza fue realizado a través del programa de SAS. 
Cuadro 1. Cultivares y Poblaciones $F^{\prime}$ utilizados en el experimento 1.

\begin{tabular}{lll}
\hline Cultivares y Poblaciones & \multicolumn{1}{c}{ Origen } & Reacción a la enfermedad \\
\hline 1-PVA-800 X BAT-1155 & Andino y Mesoamericano & Desconocido \\
2-BAT-1155 X PVA-800(R) & Mesoamericano y Andino & Desconocido \\
3-PVA-800 ICA-15399 & Andino x Andino & Desconocido \\
4-AFR-251 X BAT-1155 & Mesoamericano x Mesoamericano & Desconocido \\
5-BAT-1155 X AFR-251 R & Mesoamericano x Mesoamericano & Desconocido \\
6-AFR-251 X PVA-800 & Mesoamericano x Andino & Desconocido \\
7-ICA 15399 (Progenitor) & Andino & Intermedio \\
8-AFR-251 (Progenitor) & Mesoamericano & Resistente \\
9-BAT-1155 (Progenitor) & Mesoamericano & Susceptible \\
10-PVA-800 (Progenitor) & Andino & Resistente \\
\hline
\end{tabular}

Cuadro 2. Cultivares y Poblaciones $\mathrm{F}_{1}$ y $\mathrm{F}_{2}$ utilizados en el experimento 2 .

\begin{tabular}{lll}
\hline Cultivares y Poblaciones $\mathbf{F}_{\mathbf{1}} \mathbf{y} \mathbf{F}_{\mathbf{2}}$ & \multicolumn{1}{c}{ Origen } & Reacción a la Enfermedad \\
\hline 1.PVA 800 X BAT 1155 & Andino x Mesoamericano & Desconocido \\
2.BAT 1155 X PVA 800 (R) & Mesoamericano x Andino & Desconocido \\
3.AFR 251 X BAT 1155 & Mesoamericano x Mesoamericano & Desconocido \\
4.BAT 1155 X AFR (R) & Mesoamericano x Mesoamericano & Desconocido \\
5.AFR 251 X PVA-800 (D) & Mesoamericano x Andino & Desconocido \\
6.PVA-800 X ICA-15399 (D) & Mesoamericano x Andino & Desconocido \\
7.AFR-251 (Progenitor) & Mesoamericano & Resistente \\
8.ICA-15399 (Progenitor) & Andino & Intermedio \\
9.BAT 1155 (Progenitor) & Mesoamericano & Susceptible \\
10.PVA 800 (Progenitor) & Andino & Resistente \\
\hline
\end{tabular}

Cuadro 3. Cultivares y Poblaciones $F_{1}$ y $F_{2}$ utilizados en el experimento 3.

\begin{tabular}{lll}
\hline Cultivares y Poblaciones $\mathbf{F}_{1}$ y $\mathbf{F}_{2}$ & \multicolumn{1}{c}{ Origen } & Reacción a la Enfermedad \\
\hline AFR 251 & Mesoamericano & Resistente \\
PVA 800 & Andino & Resistente \\
AFR 251 X PVA 800 $\left(\mathrm{F}_{1}\right)$ & Mesoamericano x Andino & Resistente x Resistente \\
AFR 251 X PVA 800 $\left(\mathrm{F}_{2}\right)$ & Mesoamericano x Andino & Resistente x Resistente \\
\hline
\end{tabular}


Cuadro 4. Escala para evaluar la reacción que poseen los diferentes cultivares a la presencia del patógeno que ocasiona la mustia hilachosa.

\begin{tabular}{lcll}
\hline Grado & \% de severidad & Reacción \\
\hline 1 & 0 & \\
2 & $1-$ & 5 & RESISTENCIA \\
3 & $11-15$ & \\
4 & $1-15$ & RESISTENCIA \\
5 & $16-20$ & INTERMEDIA \\
6 & $21-40$ & \\
7 & $41-60$ & SUSCEPTIBILIDAD \\
8 & $61-80$ & \\
9
\end{tabular}

Las evaluaciones de la enfermedad fueron realizadas hasta que alguno de los tratamientos alcanzara el 100 por ciento de tejido afectado por la enfermedad.

\section{Diseño experimental y modelo genético}

El diseño experimental a utilizar en los tres experimentos fue el completamente al azar con cuatro repeticiones.

Los modelos genéticos que se usaron para los experimento dos y tres se presentan en el Cuadro 5.

Cuadro 5. Modelo genético utilizado en el experimento 2 y 3 .

\begin{tabular}{lll}
\hline Fuente & g.l. & E.C.M. \\
\hline Genotipos & $(\mathrm{t}-\mathrm{l})$ & $\mathrm{G}^{2}+\mathrm{rG}^{2} \mathrm{~g}$ \\
Error & $\mathrm{t}(\mathrm{r}-\mathrm{l})$ & $\mathrm{G}^{2}$ \\
Total & $(\mathrm{rt}-\mathrm{l})$ & \\
\hline
\end{tabular}

La heredabilidad se calculó como sigue:

$$
\begin{aligned}
& \mathrm{h}^{2}=\frac{\mathrm{G}^{2} \mathrm{~g}}{\mathrm{G}^{2} \mathrm{p}} \\
& \mathrm{G}^{2} \mathrm{p}=\underline{\mathrm{G}}^{2}+\mathrm{G}^{2} \mathrm{~g}
\end{aligned}
$$

\section{RESULTADOS Y DISCUSIÓN}

\section{Interacción aislamiento $\mathrm{x}$ cultivar}

Como se observa en el Cuadro 6 existió un efecto altamente significativo para cepa, cultivares y para la interacción cultivar $x$ cepa. Es importante observar que la interacción cultivar $\mathrm{x}$ cepa fue altamente significativa, por lo que realizó una prueba de Duncan a los datos.

Al realizar el análisis de Duncan correspondiente a este experimento se encontraron los siguientes resultados:

Como se observa en el Cuadro 7 las cepas son diferentes unas de otras dependiendo del lugar donde fueron colectadas. Se manifestaron de la siguiente manera: las cepas colectadas en Colombia y República Dominicana fueron los de menor virulenta para atacar el cultivo de frijol, la cepa Panamá 1 fue de colonización intermedia y las cepas Panamá 2 y la de Costa Rica las de mayor severidad al atacar los cultivares de frijol.

La interacción entre los aislamientos y los cultivares de frijol se manifestó al analizar la población FI de AFR251 x PVA-800 donde se encontraron seis grupos diferentes para los aislamientos de $R$. solani. Por otro lado al observar el comportamiento del cultivar BAT-1155 se forman tres grupos el Duncan, sin embargo, genotipo no se conserva el orden esperado para los aislamientos 
Cuadro 6. Análisis de Varianza para la interacción entre aislamiento de ( $R$. solani) y cultivares de Frijol.

\begin{tabular}{llll}
\hline Fuente & g.l. & \multicolumn{1}{c}{ C.M. } & Pr F \\
\hline Cultivares & 9 & $756,95533^{* *}$ & 0,0001 \\
Cepa & 5 & $8802,92000^{* *}$ & 0,0001 \\
Cultivar x Cepa & 45 & $154,87505^{* *}$ & 0,0003 \\
Error & 180 & 73,624583 & \\
Total & 239 & & \\
\hline
\end{tabular}

C.V. $=28,192711 \%$.

** Significado al 0,01 de probabilidad.

Cuadro 7. Análisis de Duncan para seis poblaciones de (R. solani) y 10 variedades y poblaciones de frijol común.

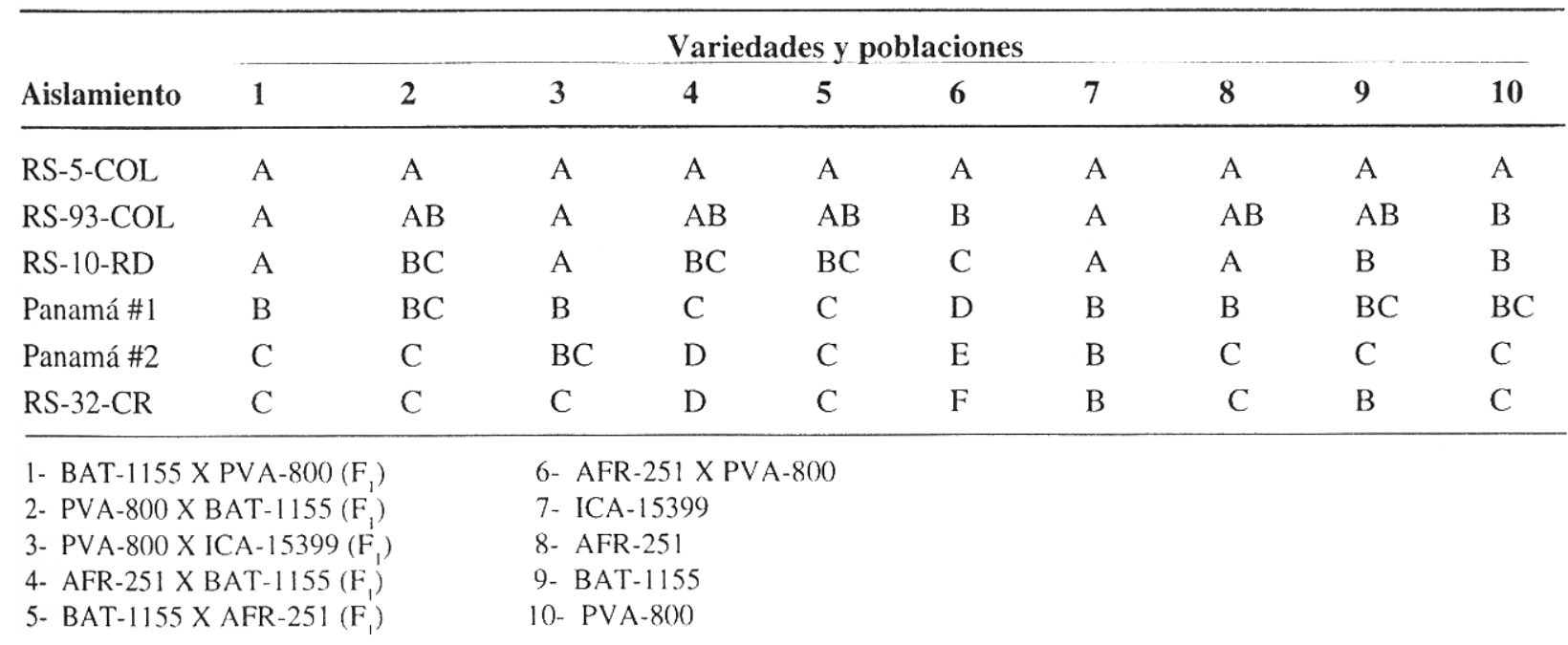

siendo el de menor virulencia el RS-5-COL y el de mayor ataque la Panamá \#2. De igual manera varía el cultivar AFR-25I donde se manifiesta el aislamiento RS-5-COL como el de menor ataque y los de mayor virulencia los aislamientos Panamá \#2 y RS-32-CR.

Hubo interacción significativa, esto indica que los datos que se obtengan en evaluaciones de ensayos y/o viveros en estos lugares no deben ser combinados, debido a que la virulencia de los aislamientos varía de acuerdo a la localidad. Esto sugiere manejar la información de acuerdo a la virulencia del aislamiento. La información que se obtenga al realizar estas evaluaciones deberá ser manejada independientemente para evitar errores en su interpretación.
Por otro lado como era de esperarse, los cultivares utilizados en esta evaluación manifestaron diferentes grados de reacción ante el ataque del patógeno. Así con las cepas RS-93-COL manifestaron su menor severidad con las poblaciones $\mathrm{F}_{1}$, BAT-1155 X PVA-800 (R) y AFR25I X BA T-1155; con la cepa RS-10-RD fue la población BA T-1155 X FR-251 (R) la que mostró severidad menor ante el ataque del patógeno; para las cepas Panamá 1 y Panamá 2 fueron los cultivares PVA-800 y AFR-25I, mientras que para la cepa RS-32-CR fue la población $\mathrm{F}_{1}$ de PVA- 800 x bat-1155 en la que causó menor daño el patógeno.

Por otro lado como era de esperarse, los cultivares utilizados en esta evaluación manifestaron diferentes grados de reacción ante el ataque del patógeno. Así con las 
cepas RS-93-COL manifestaron su menor severidad con las poblaciones $\mathrm{F}_{1}$, BAT-1155 X PVA-800 (R) y AFR251X BA T-1155; con la cepa RS-10-RD fue la población BAT-1155 X FR-251 (R) la que mostró severidad menor ante el ataque del patógeno; para las cepas Panamá 1 y Panamá 2 fueron los cultivares PVA-800 y AFR-251, mientras que para la cepa RS-32-CR fue la población $\mathrm{F}_{1}$ de PVA-800 x bat-1155 en la que causó menor daño el patógeno.

\section{Heredabilidad y complementación génica}

Para el análisis de varianza de los datos utilizados para estimar la heredabilidad en sentido amplio y la complementación génica existente entre el acervo genético mesoamericano y andino se utilizó la transformación del arco seno ya que por regla general, los datos en porcentaje tienen una distribución binomial en vez de una distribución normal.

Esta transformación se hizo mediante la fórmula:

$$
\operatorname{seno}^{-1} \mathrm{x} / 100 * 57,2958
$$

Al realizar el análisis de varianza de la $\mathrm{F}_{2}$ en la cruza número uno, es decir PVA-800 x BAT-1155 en forma directa y recíproca, donde se evaluaron ambos progenitores así como la $\mathrm{F}_{1}$ y $\mathrm{F}_{2}$ de ambos cruzamientos, se obtuvo una heredabilidad de $85,62 \%$ y $91,22 \%$ respectivamente; estos resultados indican que este caracter, resistencia a la enfermedad, es de alta heredabilidad para esta cruza. Sin embargo, Kornegay (1988) señala que aunque la evidencia empírica de los viveros de mejoramiento sugiere que la resistencia al añublo de Ascochyta, al mosaico dorado del frijol, a la mustia hilachosa, a los barrenadores de vainas (Apion spp), a la mosca africana, así como la fijación de nitrógeno en el frijol y los mecanismos genéticos de tolerancia a la sequía también pueden ser controlados poligénicamente con niveles de bajos a moderadamente altos de heredabilidad.

Por otro lado también Agrios (1985) señala que los caracteres de alta heredabilidad están basados en genes mayores, es decir resistencia cualitativa.
Sin embargo, la alta heredabilidad del caracter para esta cruza se debe básicamente a los genes de resistencia existentes que al unirse dan un alto grado de resistencia en algunas plantas de la población $\mathrm{F}_{2}$; este efecto que causan ambos acervos genéticos es el que se llama complementación génica o segregación transgresiva puesto que existe descendencia que supera a ambos progenitores y es esta descendencia la que hace que la heredabilidad se manifieste como alta para este cruzamiento.

Estos datos se encuentran en los Cuadro 8 y 9 donde se muestran el análisis de varianza para ambas cruzas así como el cálculo de varianza genética $\left(\mathrm{G}^{2} \mathrm{~g}\right)$, la varianza fenotípica $\left(\mathrm{G}^{2} \mathrm{p}\right)$ y de heredabilidad $\left(\mathrm{h}^{2}\right)$.

Para el cruzamiento número dos, AFR-251 x BAT1155 en forma directa y recíproca se encontró una heredabilidad de $94,53 \%$ y de 87,79 por ciento respectivamente indicando que en este cruzamiento la heredabilidad es alta para el caracter bajo estudio. En este caso nuevamente se manifiesta el efecto de complementación génica existente

Cuadro 8. Análisis de varianza para el cruzamiento PVA-800 x BAT-1155 (F $)(D)$.

\begin{tabular}{lrrrc}
\hline FV & GL & \multicolumn{1}{c}{ SC } & CM & ECM \\
\hline Planta & 85 & 12387,65 & 1457,37 & $\mathbf{M}_{2}$ \\
Error & 258 & 54087,45 & 209,64 & $\mathbf{M}_{1}$ \\
Total & 343 & 177964,11 & & \\
\hline
\end{tabular}

$\mathrm{CV}=34.68 \%$

PVA $-800=33.62 \% ;$ BAT $-1155=41.61 \% ; F_{1}=49.67 \%$

$\mathrm{G}^{2} \mathrm{~g}=\frac{\mathrm{M}_{2}-\mathrm{M}_{1}}{\mathrm{r}}$

$=\frac{1457,37-209,64}{4}$

$=311,93$

$\mathrm{G}^{2} \mathrm{p}=\frac{\mathrm{G}^{2}}{\mathrm{r}}+\mathrm{G}^{2} \mathrm{~g}$

$=\underline{209,64}+311,93$

4

$=364,34$ 


$$
\begin{aligned}
h^{2} & =\frac{G^{2} g}{G^{2} p} \\
& =\frac{311,93}{364,34} \\
& =0,8562
\end{aligned}
$$

Cuadro 9. Análisis de Varianza para el Cruzamiento BAT-1 155 x PVA-800 ( $\left.\mathrm{F}_{2}\right)(\mathrm{D})$.

\begin{tabular}{lrrrr}
\hline FV & GL & \multicolumn{1}{c}{ SC } & \multicolumn{1}{c}{ CM } & ECM \\
\hline Planta & 91 & 223475,80 & 2455,78 & $\mathbf{M}_{2}$ \\
Error & 269 & 58023,68 & 215,70 & $\mathrm{M}_{1}$ \\
Total & 360 & 281499,48 & & \\
\hline
\end{tabular}

$\mathrm{CV}=34,68 \%$

BAT $-1155=54,94 \%=36,64 \% ; F_{1}=50,40 \%$

$\mathrm{G}^{2} \mathrm{~g}=\frac{\mathrm{M}_{2}-\mathrm{M}_{1}}{\mathrm{r}}$

$=\frac{2455,78-215,70}{4}$

$=560,02$

$\mathrm{G}^{2} \mathrm{p}=\frac{\mathrm{G}^{2}}{\mathrm{r}}+\mathrm{G}^{2} \mathrm{~g}$

$=\frac{215,70}{4}+560,02$

$=613,94$

$\mathrm{h}^{2}=\frac{\mathrm{G}^{2} \mathrm{~g}}{\mathrm{G}^{2} \mathrm{p}}$

$=\frac{560,02}{613,94}$

$=0,9122$

para estos acervos genéticos ya que el AFR-251 ha sido considerado como resistente y el BAT-1155 como susceptible en las mismas pruebas realizadas, con anterioridad, por lo que se asume que los genes de resistencia que po- seen ambos progenitores son diferentes y complementarios.

Por otro lado si se comparan los cruzamientos de BAT-1155 x AFR-251 y AFR-251 x BAT-1155 (R); en el primer caso existieron un total de 8 plantas $\mathrm{F}_{2}$ por debajo del 10 por ciento de severidad de la enfermedad, 7 plantas entre 10 y 20 por ciento, 14 plantas entre 20 y 30 por ciento, 12 plantas entre 30,1 y 40 por ciento, 11 plantas entre 40,1 y 50 por ciento, 20 plantas entre 50,1 y 60 por ciento, 10 plantas entre 60,1 y 70 por ciento, ocho plantas entre 70,1 y 80 por ciento, 13 plantas entre 80,1 y 90 por ciento y dos plantas entre 90,1 y 100 por ciento. Mientras que para el cruzamiento de AFR-251 x BAT$1155(\mathrm{R})$ se encontraron 72 plantas $\mathrm{F}_{2}$ con el porcentaje de severidad menor del 10 por ciento, 17 plantas $F_{2}$ entre 10,1 y 20 por ciento, cinco plantas entre 20,1 y 30 por ciento, una planta entre 30,1 y 40 por ciento y tres plantas entre 60,1 y 70 por ciento de severidad. Lo que indica que existen diferencias entre la cruza directa y recíproca, al comparar la severidad promedio en las $\mathrm{F}_{1}$ de los cruzamientos directos y recíprocos $(29,36$ y 74,66 por ciento respectivamente) Pudo determinarse que no solamente existen genes del núcleo que influyendo en la resistencia sino genes del núcleo tienen que ver con esta resistencia. Son precisamente los genes del citoplasma aportados por AFR-251, los que están influyendo para que esta diferencia ocurra. Por lo tanto, este fue un cruzamiento que presenta alta heredabilidad, existe complementación génica entre ambos acervos genéticos y existen efectos citoplásmieos por parte de AFR-251.

Si fuera posible graficar el comportamiento de los cruzamientos AFR-251 x BAT-1155 y AFR-251 x PVA800 y suponer, de acuerdo a la distribución de frecuencias, que el caracter de resistencia está controlado por genes dominantes. Sin embargo, al observar el cruzamiento recíproco de BAT-1155 x AFR-251 se obtuvo una distribución de frecuencia que tiende a ser normal; este concepto reafirma aún más el hecho de que son genes del citoplasma aportados por AFR-251 los que hacen que la curva se comporte de esta manera. 
Estos resultados se muestran en los Cuadros 10 y 11 respectivamente.

Para el cruzamiento número tres, AFR-251 X PVA800 se obtuvo un valor de heredabilidad de 90,15 por ciento, el que se considera alto para este caracter (Cuadro 12). Al realizar una distribución de frecuencias se puede distinguir que existen 72 genotipos con un valor menor a $10 \%$ de severidad, siete genotipos con un porcentaje menor a 20 por ciento, un genotipo entre 20 y 30 por ciento, un genotipo entre 30 y 40 por ciento y un genotipo con un valor mayor al 40 por ciento; lamentablemente no se contaba con el cruzamiento recíproco de esta cruza para ver el efecto citoplasmático que origina el cultivar AFR-251. Para este cruzamiento el alto valor de heredabilidad

Cuadro 10. Análisis de varianza para el cruzamiento AFR-251 x BAT-1155 x PVA-800 $\left(\mathrm{F}_{2}\right)(\mathrm{D})$.

\begin{tabular}{lrrrr}
\hline FV & GL & SC & CM & ECM \\
\hline Planta & 97 & 71224,59 & 734,27 & $\mathbf{M}_{2}$ \\
Error & 293 & 11768,47 & 40,16 & $\mathbf{M}_{1}$ \\
Total & 390 & 82993,07 & & \\
\hline
\end{tabular}

$\mathrm{CV}=72,76 \%$

AFR-251 $=19,0 \%$; BAT- $1155=71,83 \% ; F_{1}=29,36 \%=$ severidad

$\mathrm{G}^{2} \mathrm{~g}=\frac{\mathrm{M}_{2}-\mathrm{M}_{1}}{\mathrm{r}}$

$=173,53$

$\mathrm{G}^{2} \mathrm{p}=\frac{\mathrm{G}^{2}}{\mathrm{r}}+\mathrm{G}^{2} \mathrm{~g}$

$=\frac{40,16}{4}+173,53$

$=183,57$

$h^{2}=\frac{G^{2} g}{G^{2} p}$

$=173,53$

183,57

$=0,9453$
Cuadro 11. Análisis de varianza para el cruzamiento BAT-1155 x AFR-251 (F $\left.{ }_{2}\right)(\mathrm{D})$.

\begin{tabular}{lrrrr}
\hline FV & GL & \multicolumn{1}{c}{ SC } & CM & ECM \\
\hline Planta & 94 & 241256,98 & 2466,56 & $\mathbf{M}_{2}$ \\
Error & 282 & 88330,44 & 313,23 & $\mathbf{M}_{1}$ \\
Total & 376 & 329587,42 & & \\
\hline
\end{tabular}

$$
\begin{aligned}
\mathrm{CV} & =37,33 \% \\
\text { BAT } & -1155=48,67 \% ; \mathrm{A} \\
\mathrm{G}^{2} \mathrm{~g} & =\frac{\mathrm{M}_{2}-\mathrm{M}_{1}}{\mathrm{r}} \\
& =\frac{2566,27-313,23}{4} \\
& =563,33 \\
\mathrm{G}^{2} \mathrm{p} & =\frac{\mathrm{G}^{2}+\mathrm{G}^{2} \mathrm{~g}}{\mathrm{r}} \\
& =\frac{313,23}{4}+563,33 \\
& =641,63 \\
\mathrm{~h}^{2} & =\frac{\mathrm{G}^{2} \mathrm{~g}}{\mathrm{G}^{2} \mathrm{p}} \\
& =\frac{563,33}{641,63} \\
& =0,8779
\end{aligned}
$$$$
\text { BAT- } 1155=48,67 \% ; \text { AFR- } 251=18,43 \% ; F_{1}=74,66 \%
$$

Cuadro 12. Análisis de varianza para el cruzamiento AFR-251 x PVA-800 $\left(\mathrm{F}_{2}\right)$.

\begin{tabular}{lrrrr}
\hline FV & GL & \multicolumn{1}{c}{ SC } & CM & ECM \\
\hline Planta & 80 & 18477,47 & 230,97 & $\mathbf{M}_{2}$ \\
Error & 242 & 5506,91 & 22,75 & $\mathbf{M}_{1}$ \\
Total & 322 & 23984,38 & & \\
\hline
\end{tabular}

$\mathrm{CV}=104,38 \%$

AFR-251 $=7,5 \% ;$ PVA- $800=18,15 \% ; F_{1}=73,75 \%$

$$
\begin{aligned}
G^{2} g & =\frac{M_{2}-M_{1}}{r} \\
& =\frac{230,97-22,75}{4}
\end{aligned}
$$

$=52,00$ 


$$
\begin{aligned}
\mathrm{G}^{2} \mathrm{p} & =\frac{\mathrm{G}^{2}}{\mathrm{r}}+\mathrm{G}^{2} \mathrm{~g} \\
& =\frac{22,75}{4}+52,00 \\
& =57.68 \\
\mathrm{~h}^{2} & =\frac{\mathrm{G}^{2} \mathrm{~g}}{\mathrm{G}^{2} \mathrm{p}} \\
& =\frac{52,00}{57,68} \\
& =0,9015
\end{aligned}
$$

obtenido se debe nuevamente a la complementación génica que existe entre los acervos mesoamericano y andino. Cabe señalar que las reacciones de resistencia estuvieron dados por la hipersensibilidad que se manifestó como un amarillamiento que varió de lento a rápido en las hojas inoculadas con el patógeno, así como también se observaron reacciones de necrosis vascular que también fueron llamadas reacciones de hipersensibilidad.

Para el cruzamiento número cuatro, donde se cruzó PV A-800 X ICA-15399 (D), nuevamente se observó un porcentaje de heredabilidad de 89,34 por ciento el que al igual a los anteriores fue considerado como alto para el caracter que se estaba estudiando, Este efecto se debió posiblemente a la existencia de genes de resistencia que tienen tanto el PVA-800 como el ICA-15399 y que al unirse causan efectos de acumulación y complementación entre sí; este efecto es el que se conoce como segregantes transgresivos. El análisis de varianza se muestra en el Cuadro 13.

Por otro lado, Vander Plank (1968) al hacer una discusión sobre resistencia vertical y horizontal señala que en un análisis de varianza donde se incluyan cepas y variedades y se manifieste la interacción significativa, ésta será debido a efectos de resistencia vertical, cuando la interacción no es significativa es debido a que se está manifestando la resistencia horizontal y cuando se manifieste cepas, variedades y variedades por cepas como significativo es que se poseen ambos tipos de resistencia.
Sin embargo, en nuestro caso que poseemos tanto variedades, cepas y variedades por cepa como significativos, lo que ocurre es que la acumulación de genes ha llegado a tal extremo que permite que se confundan los efectos de resistencia horizontal con los de resistencia vertical, como son, las reacciones de hipersensibilidad, característica típica de la resistencia vertical.

Conociendo como se ha manejado los programas de mejoramiento en la región centroamericana, sabemos que se han ido acumulando genes de resistencia con el paso de los años y al juntar genotipos de dos acervos genéticos que han sido manejados independientemente para este carácter, es obvio que deberán obtenerse genotipos superiores.

Cuadro 13. Análisis de varianza para el cruzamiento PVA-800 x ICA-15399 (F) (D).

\begin{tabular}{lrrrr}
\hline FV & GL & \multicolumn{1}{c}{ SC } & CM & ECM \\
\hline Planta & 93 & 250532,53 & 2693,89 & $\mathbf{M}_{2}$ \\
Error & 377 & 79528,41 & 287,11 & $\mathbf{M}_{1}$ \\
Total & 370 & 330060,94 & & \\
\hline
\end{tabular}

$$
\begin{aligned}
\mathrm{CV} & =32,43 \% \\
\mathrm{BAT} & -1155=48,67 \% ; \text { AFR- } 251=18,43 \% ; \mathrm{F}_{1}=74,66 \% \\
\mathrm{G}^{2} \mathrm{~g} & =\frac{\mathrm{M}_{2}-\mathrm{M}_{1}}{\mathrm{r}} \\
& =\frac{2693,89-287,11}{4} \\
& =601,70 \\
\mathrm{G}^{2} \mathrm{p} & =\frac{\mathrm{G}^{2}+\mathrm{G}^{2} \mathrm{~g}}{\mathrm{r}} \\
& =\frac{287,11}{4}+601,70 \\
& =673,47 \\
\mathrm{~h}^{2} & =\frac{\mathrm{G}^{2} \mathrm{~g}}{\mathrm{G}^{2} \mathrm{p}} \\
& =\frac{601,70}{673,47} \\
& =0,8934
\end{aligned}
$$




\section{CONCLUSIONES Y RECOMENDACIONES}

1- El análisis de varianza para el experimento donde se evaluó la interacción variedad x cepa, muestra diferencias altamente significativas tanto para cepa, variedades $\mathrm{x}$ cepa.

2- La agresividad de las cepas varió dependiendo de su lugar de origen. Así las cepas de Colombia y República Dominicana causan el menor daño a las plantas de frijol, el aislamiento Panamá 2 y Costa Rica son los que mayor daño causan a este cultivo.

3- La cepa RS-32-CR, resultó ser la más virulenta de todas, rompiendo la resistencia mostrada en evaluaciones éstas no se pueden diferenciar estadísticamente cuando se inocularon con esta cepa.

4- La heredabilidad mostrada por todos los cruzamientos fue alta, lo que indica que existe complementación génica entre el acervo mesoamericano y andino, respectivamente.

5- El cruzamiento AFR-251 y BAT-1155, en forma directa y recíproca, mostraron diferencias en $\mathrm{F}_{1}$ y la $\mathrm{F}_{2}$, lo que indica que la resistencia a la enfermedad está controlada por gene s del citoplasma y gene s del núcleo.

6- El tipo de resistencia que mostraron los diferentes cruzamientos evaluados fue el de resistencia horizontal y no el de resistencia vertical.

7- Se recomienda la metodología de inoculación usada en la presente investigación como una manera más segura y más fácil de obtener materiales de alta resistencia a este patógeno.

8- Esta metodología representa una excelente ventaja para tamizar grandes volúmenes de germoplasma porque permite ahorrar tiempo, espacio y dinero.

\section{LITERATURA CITADA}

ACOST A, M. 1988. Manejo integrado de la mustia hilachosa causada por Thanatephorus cucumeris (Frank) Donk en el frijol común Phaseolus vulgaris L. Tesis de Maestría. Universidad Nacional de Colombia. Bogotá, Colombia. 6, $13,15 \mathrm{p}$.

AGRIOS, N. G. 1985. Fitopatología. Editorial Limusa, México. 93, 99, $106 \mathrm{p}$.

BEEBE, S. 1986. In Memorias del Segundo Taller de Mustia Hilachosa. San José, Costa Rica. 124 p.

FRIAS, G. 1991. Variabilidad patogénica de Thanatephorus cucumeris $=$ Rhizoctonia solani, agente causal de la mustia hilachosa del frijol. In Memorias del Congreso Nacional de Fitopatología. Puebla de los Angeles, México. 84 p.

GALVEZ, E.; GUZMAN, P.; CASTAÑO, M. 1980. La Mustia Hilachosa. Problemas de la producción de frijol, enfermedades, insectos, limitaciones edáficas y climáticas de $P h a$ seolus vulgaris L. Centro Internacional de Agricultura Tropical. Cali, Colombia. 101-110 p.

KORNEGAY, J. 1988. Conceptos básicos en genética cuantitativa relevantes al mejoramiento de frijol común. In: Temas actuales en mejoramiento genético del frijol común. Memorias del Taller Internacional de Mejoramiento Genético de Frijol común. Memorias del Taller Internacional de Mejoramiento Genético de Frijol. CIAT. Cali, Colombia. 202 p.

RODRíGUEZ, E.; GONZÁLEZ, F. 1990. Resultados de Proyectos Experimentales 1988, 1989. IDIAP. Caisán. Panamá.

RODRIGUEZ, E. 1992. Heredabilidad de la Resistencia a la Mustia Hilachosa Thanatephorus cucumeris (Frank), Donk) en Cultivares y Poblaciones $\mathrm{F}_{1}$ y $\mathrm{F}_{2}$ de Frijol Común Phaseolus vulgaris L.). Tesis de Maestría. Universidad Autónoma Agraria Antonio Narro. México. 72 p. 